\title{
IMPOSTO SOBRE O RENDIMENTO DAS PESSOAS SINGULARES (IRPS) EM CABO VERDE: EVOLUÇÃO HISTÓRICA E RECEITAS COBRADAS EM 2008-2015
}

\section{CAPE VERDE IRS INCOME TAX: HISTORICAL EVOLUTION AND REVENUE COLLECTED IN 2008-2015}

\author{
Celina Lizardo ${ }^{1}$ orcid.org/0000-0002-7335-4649 \\ Paulo Ribeiro ${ }^{2}$ orcid.org/0000-0001-5662-6318
}

\begin{abstract}
Resumo: O estudo em curso visa demarcar a evolução do Imposto sobre o Rendimento das Pessoas Singulares (IRPS) em Cabo Verde, desde a época colonial até a atualidade, e verificar a oscilação deste imposto, no período de 2008 a 2015, com o objetivo de delinear propostas de medidas para melhorar a sua cobrança. O método utilizado foi o estudo de caso com recurso a recolha documental, enquadrado pela legislação fiscal e Pareceres das Contas Gerais do Estado, proferidos pelo Tribunal de Contas de Cabo Verde. Os resultados indicam que este imposto passou por 4 fases, inicialmente conhecido como imposto de defesa (1939), posteriormente como imposto complementar sobre os rendimentos e imposto profissional (1963), depois assumiu o cariz de Imposto Único sobre o Rendimento das Pessoas Singulares (1996) e na fase atual adotou a figura de Imposto sobre o Rendimento das Pessoas Singulares (IRPS) (2015). A oscilação deste imposto, entre 2008 e 2015, induziu um acréscimo médio de receitas de 102.712 milhares de Escudos Cabo-Verdianos
\end{abstract}

${ }^{1}$ Inspetora Tributária Superior - Direção Nacional de Receitas do Estado de Cabo Verde. E-mail: celinalizardo@hotmail.com

${ }^{2}$ Professor Auxiliar - Departamento de Economia, Gestão e Ciências Sociais da Universidade Católica Portuguesa. E-mail: pribeiro@viseu.ucp.pt 
(2,2\% das receitas do IRPS), porém, o stock médio de dívidas deste imposto, neste período, ascendeu a 4,3\% das receitas de IRPS. Desta constatação surgirão um conjunto de propostas de medidas para aumentar a eficácia da sua cobrança que envolvem o controlo da dívida fiscal com cruzamento de informações. Pretende-se, por um lado, purificar e cobrar estas dividas, e, por outro, promover um forte investimento na educação/consciencialização fiscal.

Palavras-Chave: Imposto sobre o rendimento, Pessoas singulares, Receitas cobradas

Abstract: The ongoing study aims to trace the evolution of the Personal Income Tax (IRPS) in Cape Verde, from colonial times to the present day, and verify the oscillation of this tax from 2008 to 2015. This, in order to outline proposals for measures to improve its collection. The method used was the case study with recourse to documentary collection, framed by the tax legislation and opinions of the general accounts of the State issued by the Court of Auditors of Cape Verde. The results indicate that this tax went through 4 stages, initially known as the defense tax (1939), later as a supplementary tax on income and professional tax (1963), then assumed the character of Single Tax on Personal Income (1996) and in the current stage adopted the figure of Individual Income Tax (IRPS) (2015). The fluctuation of this tax, between 2008 and 2015, led to an average increase in revenues of 102,712 thousand capeverdean Escudos (2.2\% of IRPS revenues, however, the average stock of debts of this tax in this period amounted to $4.3 \%$ of income from IRPS. From this finding will be a set of proposals for measures to increase the effectiveness of its collection that involve the control of fiscal debt with crossover of information. The aim is, on the one hand, to purify and collect these debts, and, on the other hand, to promote a strong investment in fiscal education / awareness.

Keywords: Income tax, Individuals, Revenue collected 


\section{INTRODUÇÃO}

Cabo Verde é um país constituído por um pequeno arquipélago com um clima predominantemente árido e possui uma produção agrícola e industrial limitada (Vasques, 2016).

O país regia-se inicialmente pelas legislações fiscais ultramarinas, conforme o Regulamento Geral da Administração da Fazenda Pública, datado de 4 de janeiro de 1870 (CLNU, 1902). As legislações fiscais aplicadas nas colónias portuguesas, das quais Cabo Verde fazia parte, começaram a suportar reformas desde 1901, com a introdução do Regulamento Geral da Administração da Fazenda, da sua fiscalização superior e da contabilidade pública, sancionado pelo Decreto de 3 de outubro de 1901 (CLNU, 1902). A partir de 1901 foi criada uma série de impostos, aplicada nas províncias ultramarinas, abrangendo também Cabo Verde. Nos anos 60 o país passou por uma profunda reforma do sistema fiscal, levado a cabo pela metrópole portuguesa, no propósito de criar uma zona de comércio livre à volta das suas províncias ultramarinas (Vasques, 2016). A reforma fiscal prosseguiu-se nos anos 70, após a independência de Cabo Verde (1975) ( art. $\left.^{\circ} 3 .^{\circ}, \mathrm{RII}\right)$ e nos anos 90, após a entrada da democracia no país (1991) (Vasques, 2016).

No ano 2015 foi introduzida uma nova fase de reforma fiscal, suportada pela Lei n. ${ }^{\circ} 78 / \mathrm{VIII} / 2014$, de 31 de dezembro e pela Lei n. $^{\circ}$ 82/VIII/2014, de 8 de janeiro. Esta fase induziu a entrada da declaração eletrónica de rendimentos no país (Portaria n. ${ }^{\circ}$ 78/2015, de 31 de dezembro).

O estudo em curso segue a esteira do Imposto sobre os Rendimentos das Pessoas Singulares (IRPS), a partir do ano 2008, data em que surgiu "a crise financeira internacional" (De Paula \& Ferrari Filho, 2011, p. 316). O período de análise compreende o período entre 2008 e 2015, data em que a última Conta Geral do Estado foi validada pelo Tribunal de Contas de Cabo Verde.

Após o ciclo deliberadamente expansionista da política orçamental que se seguiu à crise internacional, no período de 2008 a 2015, Cabo Verde tem vindo a denotar uma trajetória lenta, mas gradual, de redução do défice orçamental, o que se traduziu num aumento continuado da dívida pública (Banco de Portugal, 2015), não obstante o conjunto de reformas 
introduzidas na esfera tributária. Esta situação deve-se, em parte, à fraca dinâmica da atividade económica de alguns setores (comércio, comunicações e construção civil) que se refletiu negativamente na arrecadação de receitas fiscais (Banco de Portugal, 2015).

O Governo tem envidado esforços no sentido de estimular a cobrança das dívidas fiscais ditadas, nomeadamente, através do Decreto-Lei n. ${ }^{\circ}$ 35/2013 de 24 de setembro e do Decreto-Lei n. ${ }^{\circ}$ 72/2015, de 31 de dezembro, mas os objetivos preconizados para a regularização destas dívidas não tiveram o impacto desejado (PCGE, 2015).

$\mathrm{Na}$ senda da dita conjuntura, torna-se pertinente buscar meios que permitam melhorar a cobrança de receitas e reduzir a dívida pública. Este quadro despertou-nos interesse para a observação desta matéria, tendo a investigação sido direcionada para a oscilação das receitas do IRPS.

\section{ENQUADRAMENTO LEGAL / REVISÃO DE LITERATURA}

Emana a Constituição da República de Cabo Verde (CRCV) que, todo o cidadão tem o dever de pagar as contribuições e impostos estabelecidos nos termos da Lei (al. g), art. ${ }^{\circ}$ 85. ${ }^{\circ}, \mathrm{CRCV}$ ). As contribuições estão vinculadas a uma contraprestação, que é o típico pressuposto das taxas, porém, o pressuposto dos impostos assenta essencialmente na capacidade contributiva (Cardina, 1999).

Os impostos principais que constituem o painel do sistema fiscal caboverdiano são oriundos da época colonial (Vasques, 2016), desde o ano de 1870, marcado com o Regulamento Geral da Administração da Fazenda, datado de 4 de outubro (CLNU, 1902), que evoluiu para o Regulamento Geral da Administração da Fazenda da sua fiscalização superior e da contabilidade pública nas províncias ultramarinas, sancionado pelo Decreto de 3 de outubro de 1901 (CLNU, 1902). Estes Regulamentos foram aplicados nas colónias portuguesas, das quais Cabo Verde fazia parte. A partir de 1901 foram criados uma série de impostos aplicados nas províncias ultramarinas, abrangendo também Cabo Verde. Nos anos 60 foi levado "a cabo uma reforma profunda do sistema fiscal colonial português" (Vasques, 2016, p. 953) tendo esta reforma também impacto em Cabo Verde, com a aprovação das subsequentes legislações: 
1. Regulamento da Contribuição Industrial (RCI), aprovado pelo Diploma Legislativo n. ${ }^{\circ} 1542$, de 12 de junho de 1963, que veio revogar toda a legislação anterior sobre a matéria da Contribuição Industrial (art. ${ }^{\circ} 70 .^{\circ}$, Regulamento da Contribuição Industrial);

2. Regulamento do Imposto Profissional (RIP), regido pelo Diploma Legislativo n. ${ }^{\circ} 1543$, de 12 de junho de 1963, onde se revogou toda a legislação que estava a tributar os que trabalhavam por conta de outrem e os que exerciam qualquer profissão liberal e técnica (art. ${ }^{\circ}$ 57. ${ }^{\circ}$, Regulamento do Imposto Profissional);

3. Regulamento do Imposto Complementar sobre os rendimentos (RIC), aprovado pelo Diploma Legislativo n. ${ }^{\circ} 1545$, de 12 de junho de 1963 e que entrou em vigor após a extinção do imposto de defesa

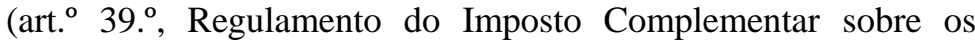
rendimentos), que foi criado pelo Decreto n. ${ }^{\circ} 30117$, de 8 de dezembro de 1939 (n. ${ }^{\circ}$ 1, corpo do Diploma Legislativo n..$^{\circ} 1545$, de 12 de junho de 1963);

4. Regulamento da Contribuição Predial (RCP), regido pelo Diploma Legislativo n. ${ }^{\circ}$ 1544, de 12 de junho de 1963, que revogou o Regulamento da Contribuição Predial, aprovado pelo Diploma Legislativo n. ${ }^{\circ}$ 315, de 29 de agosto de 1931, e demais legislações que o tenha aditado ou alterado (art. ${ }^{\circ} 147 .^{\circ}$, Regulamento da Contribuição Predial);

5. Código do Imposto de Capitais, aprovado pelo Decreto-Lei n. ${ }^{\circ} 44$ 561, de 10 de setembro de 1962.

Após a independência de Cabo Verde, em 1975, foram criadas duas categorias de impostos ( art. $\left.^{\circ} 3 .^{\circ}, \mathrm{RII}\right)$ :

1. Imposto sobre os Rendimentos de Petróleo e seus derivados, criado pelo Decreto-Lei n. ${ }^{\circ} 11-\mathrm{B} / 77$, de 28 de janeiro e aprovado pelo Decreto n. ${ }^{\circ} 130 / 77$, de 31 de dezembro;

2. Imposto de Capitais, criado pelo Decreto-Lei n. ${ }^{\circ} 11-\mathrm{A} / 77$, de 28 de janeiro e regulamentado pelo Decreto n. ${ }^{\circ} 129 / 77$, de 31 de dezembro.

Na década de 90, com as primeiras eleições democráticas em 1991, estabeleceu-se a reforma do sistema fiscal como uma das principais prioridades, como afirma Vasques, 2016, p. 956 "a reforma dos impostos sobre o rendimento surgiu em primeiro lugar". No intuito de garantir a 
sustentabilidade desta reforma foram criadas as regras gerais para a liquidação e cobrança de impostos, pelo Código Geral Tributário, em 1992, e pelo Código de Processo Tributário, em 1993 (Vasques, 2016).

Em 1993 foi criado o Regulamento do Imposto Industrial (RII), que veio substituir e revogar: o Regulamento da Contribuição Industrial, de 1963 (n..$^{\circ}$ 2, art. $\left.{ }^{\circ} 3 .^{\circ}, \mathrm{RII}\right)$, o Regulamento do Imposto Complementar, na parte referente à tributação de empresas, também de 1963 (art. ${ }^{\circ} 4 .^{\circ}, \mathrm{RII}$ ), a Contribuição de Juros que datava de 1933, o Imposto sobre os Rendimentos do Petróleo e o Imposto de Capitais, ambos aprovados em 1977 e o Imposto da Produção de Cana Sacarina (n. ${ }^{\circ} 1$, art. ${ }^{\circ} 3 .^{\circ}$, RII).

Em 1995-1996, "um novo Imposto Único sobre os Rendimentos (IUR) entrou em vigor, que foi aplicado quer a pessoas singulares quer a pessoas coletivas" (Vasques, 2016, p. 956) e este IUR veio substituir o Imposto Industrial (consagrado no RII, que era aplicado a empresas desde 1993) e os impostos, Profissional e Complementar, na vertente da tributação pessoal. Na ótica da tributação de empresas o IUR passou a ser designado de Imposto Único sobre o Rendimento das Pessoas Coletivas (IUR-PC) e na vertente da tributação pessoal o IUR passou a ser designado de Imposto Único sobre o Rendimento das Pessoas Singulares (IUR-PS) (Decreto-Lei n. ${ }^{\circ} 1 / 96$, de 15 de janeiro). O IUR-PS é um imposto estadual - nacional, pessoal e tendencialmente subjetivo, pois o seu apuramento toma em consideração a situação pessoal e familiar do contribuinte - de taxa variável, com progressividade por escalões de rendimentos, transformando-se num imposto proporcional (Catarino \& Soares, 2017).

A partir de 1996 o imposto sobre o rendimento tem vindo a passar por reformas contínuas, o que pode ser demonstrado pela entrada em vigor das seguintes Leis:

1. Lei n. ${ }^{\circ} 82 / \mathrm{VIII} / 2014$, de 8 de janeiro, que tributa o rendimento das pessoas coletivas (IRPC).

2. Lei n. ${ }^{\circ} 78 / \mathrm{VIII} / 2014$, de 31 de dezembro, que tributa o rendimento global das pessoas singulares (IRPS), onde a tributação de pessoas singulares com rendimentos de trabalho dependente passou a ser feita pela retenção na fonte, exercida pela fonte pagadora, com a possibilidade do contribuinte declarar o seu rendimento, caso entender, para efeito de tributação final. Vale salientar que na modalidade anterior de tributação, conforme o Decreto-Lei n. $^{\circ}$ 
1/96, de 15 de janeiro, era a fonte pagadora a fazer a retenção na fonte mas o contribuinte era obrigado a declarar o seu rendimento para efeito de tributação final. A retenção na fonte evidencia uma extensão da substituição tributária, onde, a fonte pagadora é obrigada a deduzir às remunerações dos seus trabalhadores uma fração dos seus rendimentos, a título de pagamento do imposto (Bicho \& Magno, 2007).

A entrada em vigor das novas Leis de tributação sobre os rendimentos ocorreu em 2015 e induziu a entrega da declaração de rendimentos por transmissão eletrónica (n. ${ }^{\circ}$ 2, art. $^{\circ}$ 1. $^{\circ}$, Portaria n. ${ }^{\circ}$ 78/2015, de 31 de dezembro).

Constituíram ainda fontes relevantes para o decurso da nossa investigação, os Pareceres anuais das Contas Gerais do Estado proferidos pelo Tribunal de Contas de Cabo Verde, a mando da Assembleia Nacional, tendo em vista a validação das contas apresentadas pelo Governo ( art. $^{\circ} 31 .^{\circ}$, Lei n. 77/V/98, de 7 de dezembro), até ao dia 31 de dezembro do ano seguinte àquele a que respeita a referida conta (al. a), art. $\left.^{\circ} 178 .^{\circ}, \mathrm{CRCV}\right)$.

A averiguação da evolução da cobrança do IRPS, conjuntamente com a observação do stock da dívida deste imposto sobre as receitas cobradas em IRPS, contribuíram sobremaneira para delinear as propostas de medidas para melhorar esta cobrança. O stock da dívida fiscal corresponde às dívidas fiscais acumuladas até 31 de dezembro de cada ano (PCGE, 2015), e a dívida fiscal refere-se a "dívidas dos contribuintes decorrentes do não pagamento ao Estado dos impostos liquidados a data de 31 de dezembro de cada ano" (PCGE, 2015, p. 99). O referido stock tem impacto negativo no Produto Interno Bruto (PIB), tendo em consideração que o PIB é calculado pela "soma das remunerações do trabalho, dos impostos líquidos de subsídios sobre a produção e importação e do excedente bruto de exploração" (INE, 2013, p. 2).

$\mathrm{Na}$ senda deste estudo foram adotados/operacionalizados alguns conceitos que vão de acordo com as linhas definidas para a estratégia desta investigação, a saber:

1. Imposto sobre o Rendimento das Pessoas Singulares (IRPS): abarca o Imposto Único sobre o Rendimento das Pessoas Singulares (IURPS), em vigor na data de 1996 até 2014 e o Imposto sobre o 
Rendimento das Pessoas Singulares (IRPS) que começou a vigorar a partir de janeiro de 2015;

2. Stock da dívida fiscal de IRPS: dívidas fiscais de IRPS acumuladas até 31 de dezembro de cada ano, delimitadas ao período de 2008 a 2015, seguindo a esteira do PCGE (2015);

3. Dívida fiscal de IRPS: dívida, a que os contribuintes tenham conhecimento, decorrente do não pagamento ao Estado do IRPS, na data de 31 de dezembro de cada ano, delimitada aos anos de 2008 a 2015.

4. Receitas fiscais: receitas do Estado que são arrecadadas pela Direção Geral das Contribuições e Impostos e pela Direção Geral das Alfândegas, conforme PCGE (2010).

5. Produto Interno Bruto (PIB): somatório das remunerações do trabalho, dos impostos líquidos de subsídios sobre a produção e importação e do excedente bruto de exploração, conforme (INE, 2013).

\section{METODOLOGIA DA INVESTIGAÇÃO}

No decurso da nossa investigação pudemos observar qual o comportamento das receitas cobradas em Imposto sobre o Rendimento das Pessoas Singulares no período de 2008 a 2015. Numa ótica de enquadramento histórico observámos a evolução do Imposto sobre o Rendimento das Pessoas Singulares, desde a época colonial até a atualidade e verificámos a oscilação deste imposto no período de 2008 a 2015 , tendo em vista delinear propostas de medidas para melhorar a sua cobrança. A linha de investigação foi direcionada para traçar a evolução do Imposto sobre o Rendimento das Pessoas Singulares, verificar a oscilação das receitas cobradas na esfera do referido imposto, elencar os parâmetros que contribuíram para a oscilação destas receitas e apresentar propostas de medidas para melhorar a cobrança deste imposto.

O estudo foi realizado na Direção Nacional de Receitas do Estado (DNRE), instituição governamental responsável pela área das finanças, que administra a Direção Geral das Alfândegas, e a Direção Geral das Contribuições e Impostos que "tem por incumbência administrar os impostos, taxas, multas e outras receitas que lhe forem outorgadas por lei 
(Portal DNRE, 2017). A DNRE dispõe de uma equipa formada por 362 colaboradores, onde $55,9 \%$ são do sexo feminino e $44,1 \%$ são do sexo masculino, 4,7\% possuem o ensino básico, $22.9 \%$ detêm o ensino secundário, 6,4\% possuem formação profissional, 5,5\% são bacharéis, $51,3 \%$ são licenciados, $8,9 \%$, são mestres, e $0,4 \%$ são doutorados (DNRE, 2017).

O método utilizado foi o estudo de caso, que se traduz numa abordagem caracterizada por um plano de investigação que envolve uma análise intensiva e detalhada de um caso (Coutinho \& Chaves, 2002).

A pesquisa documental, primeira etapa do estudo, foi centrada na recolha de informações constantes nos Pareceres das Contas Gerais do Estado, proferidos pelo Tribunal de Contas de Cabo Verde (TCCV) e pelas informações fornecidas pela Unidade de Tecnologias de Informação e Comunicação (UTIC). "O Tribunal de Contas é o órgão supremo da fiscalização da legalidade das despesas públicas e de julgamento das contas que a lei mandar submeter-lhe" (artigo $219^{\circ}, \mathrm{CRCV}$ ). A UTIC é a unidade que alimenta o cadastro fiscal dos contribuintes, embora com as suas limitações (Campos, 2017, p. 11).

$\mathrm{Na}$ segunda etapa do estudo colocámos o enfoque nos Pareceres das Contas Gerais do Estado, que nos permitiu depurar a evolução das receitas do Imposto sobre o Rendimento das Pessoas Singulares (IRPS) e estabelecer propostas de medidas para melhorar a sua cobrança.

A terceira etapa centrou-se na seleção e análise de variáveis demográficas e organizacionais, com o objetivo de constituir um corpus satisfatório e esgotar todas as pistas capazes de fornecer informações interessantes (Cellard, 2008). As variáveis demográficas possibilitaram a determinação do perfil dos colaboradores da instituição a que se refere o local do estudo, tendo em consideração a teoria de Fortin (2009), que considera as variáveis demográficas como propriedades que permitam traçar o perfil das caraterísticas dos sujeitos. As variáveis organizacionais serviram para contextualizar a análise do comportamento das receitas cobradas em IRPS e o conjunto das medidas propostas para melhorar a cobrança deste imposto, tendo em consideração que as variáveis organizacionais se relacionam com a "otimização dos sistemas sociotécnicos, incluindo sua estrutura organizacional, políticas e processos" (Abrantes, 2011, p. 4). 
Por fim, identificam-se e propõem-se medidas para melhorar a cobrança do IRPS, baseadas na análise dos parâmetros que contribuíram para a oscilação deste imposto, nas informações referentes ao stock da dívida do IRPS, nas recomendações apresentadas pelo Tribunal de Contas, nas deficiências que debilitem a cobrança deste imposto e nas informações fornecidas pela UTIC.

\section{RESULTADOS}

No quadro I apresenta-se um resumo da evolução histórica dos impostos cobrados em Cabo Verde até à instituição do IRPS em 2015.

\section{Quadro I}

Evolução histórica do IRPS

\begin{tabular}{|c|c|c|c|}
\hline Data & Impostos Criados & Referências & Observação \\
\hline 1939 & Imposto de defesa & $\begin{array}{l}\text { Decreto } n^{0} 30117 \text {, de } 8 \text { de } \\
\text { Dezembro de } 1939\end{array}$ & \\
\hline 1963 & $\begin{array}{l}\text { Imposto complementar } \\
\text { sobre os rendimentos }\end{array}$ & $\begin{array}{l}\text { Diploma Legislativo n. } \\
1545 \text {, de } 12 \text { de Junho de } \\
1963 \text { que aprovou o } \\
\text { Regulamento do Imposto } \\
\text { Complementar sobre os } \\
\text { rendimentos }\end{array}$ & $\begin{array}{l}\text { Substituiu o imposto de } \\
\text { defesa }\end{array}$ \\
\hline 1963 & Imposto profissional & $\begin{array}{l}\text { Diploma Legislativo } \text { n. }^{\circ} \\
1543 \text {, de } 12 \text { de Junho } \\
\text { de } 1963 \text { (RTA, 1992, p. } 3 \text { ) }\end{array}$ & \\
\hline 1996 & $\begin{array}{l}\text { Imposto Único sobre o } \\
\text { Rendimento das Pessoas } \\
\text { Singulares (IUR-PS) }\end{array}$ & & $\begin{array}{l}\text { Substituiu o imposto } \\
\text { complementar na vertente } \\
\text { de pessoas singulares e o } \\
\text { imposto profissional }\end{array}$ \\
\hline 2015 & $\begin{array}{l}\text { Imposto sobre o Rendimento } \\
\text { das Pessoas Singulares (IRPS) }\end{array}$ & & $\begin{array}{l}\text { Substituiu o Imposto Único } \\
\text { sobre o Rendimento de } \\
\text { Pessoas Singulares (IUR- } \\
\text { PS) }\end{array}$ \\
\hline
\end{tabular}

Fonte: Elaboração própria

O Quadro I demonstra que em 1963 o Imposto Complementar veio substituir o Imposto de Defesa (datado de 1939). Os impostos, Complementar e Profissional (datados de 1963), foram revogados em 1996, com a entrada em vigor do Imposto Único sobre o Rendimento das pessoas Singulares (IUR-PS) e a partir do ano 2015 o IUR-PS foi 
derrogado em detrimento do Imposto sobre o Rendimento das Pessoas Singulares (IRPS).

No propósito de contextualizar o panorama macroeconómico do IRPS no período de 2008 a 2015, é apresentado de seguida o Quadro II.

\section{Quadro II}

Panorama do IRPS de 2008 a 2015 e ambiente macroeconómico

\begin{tabular}{|c|c|c|c|c|c|c|c|c|c|}
\hline Designação & 2008 & 2009 & 2010 & 2011 & 2012 & 2013 & 2014 & 2015 & $\begin{array}{c}\text { Média } \\
\text { 2008 a } 2015 \\
\end{array}$ \\
\hline Peso do IR-PS nas receitas fiscais & $16,3 \%$ & $17,4 \%$ & $17,6 \%$ & $16,5 \%$ & $18,1 \%$ & $17,1 \%$ & $18,5 \%$ & $17,5 \%$ & $17,4 \%$ \\
\hline Peso do IR-PS nas receitas gerais do Estado & $12,2 \%$ & $11,9 \%$ & $11,7 \%$ & $16,5 \%$ & $13,6 \%$ & $12,7 \%$ & $14,0 \%$ & $12,4 \%$ & $13,1 \%$ \\
\hline Peso do IR-PS no PIB & $4,1 \%$ & $3,5 \%$ & $3,7 \%$ & $3,3 \%$ & $3,3 \%$ & $3,1 \%$ & $3,2 \%$ & $3,4 \%$ & $3,5 \%$ \\
\hline GAP orçamental IR-PS (\%) & $2,6 \%$ & $-17,0 \%$ & $-9,4 \%$ & $-5,8 \%$ & $-6,2 \%$ & $-16,7 \%$ & $-11,0 \%$ & $4,1 \%$ & $-7,4 \%$ \\
\hline édia anual & $6,8 \%$ & $1,0 \%$ & $2,1 \%$ & $4,5 \%$ & $2,5 \%$ & $1,5 \%$ & $-0,2 \%$ & $0,1 \%$ & $2,3 \%$ \\
\hline Crescimento anual de receitas & $2,6 \%$ & $-3,1 \%$ & $3,3 \%$ & $-4,4 \%$ & $-3,4 \%$ & $2,8 \%$ & $-5,5 \%$ & $21,0 \%$ & $1,7 \%$ \\
\hline Crescimento do PIB & $6,7 \%$ & $6,1 \%$ & $6,8 \%$ & $1,8 \%$ & $1,6 \%$ & $2,9 \%$ & $0,6 \%$ & $1,0 \%$ & $3,4 \%$ \\
\hline Sock da dívida fiscal sobre as receitas cobradas & $11,4 \%$ & $16,5 \%$ & $26,2 \%$ & $25,3 \%$ & $30,4 \%$ & $32,3 \%$ & $82,0 \%$ & $78,4 \%$ & $37,8 \%$ \\
\hline
\end{tabular}

Fonte: Dados de PCGE (2008 a 2015)

No Quadro II é possível observar o peso médio do IRPS nas receitas fiscais $(17,4 \%)$ e nas receitas gerais do Estado $(13,1 \%)$, no período de 2008 a 2015. O peso médio do IRPS no Produto Interno Bruto (PIB) é de $3,5 \%$, sendo que, o GAP orçamental deste IRPS, que resulta da diferença entre as receitas cobradas e as receitas orçamentadas, apresenta um desvio médio de $-7,4 \%$. Este $G A P$ negativo permite-nos observar que a meta da cobrança do IRPS, no referido período, não foi atingida, em 7,4\%, pelo que urge a necessidade da administração fiscal aprimorar para o aumento da cobrança deste imposto.

Os resultados expurgados, referentes à oscilação das receitas cobradas em IRPS no período de 2008 a 2015, encontram-se retratados no Quadro III, a seguir apresentado. 


\section{Quadro III}

Oscilação do IRPS (valores em milhares de ECV)

\begin{tabular}{crc}
\hline $\begin{array}{c}\text { Período } \\
\text { de arrecadção }\end{array}$ & \multicolumn{2}{c}{$\begin{array}{c}\text { Evolução de IR-PS } \\
\text { Valores }\end{array}$} \\
\hline 2008 & 319.510 & $7,0 \%$ \\
2009 & -371.318 & $-7,7 \%$ \\
2010 & 191.810 & $4,3 \%$ \\
2011 & 231.833 & $5,0 \%$ \\
2012 & 116.684 & $2,4 \%$ \\
2013 & -200.326 & $-4,2 \%$ \\
2014 & 205.036 & $4,3 \%$ \\
2015 & 328.463 & $6,6 \%$ \\
Média 2008 a 2015 & 102.712 & $2,2 \%$ \\
\hline
\end{tabular}

Fonte: Dados de PCGE (2008 a 2015)

A oscilação das receitas cobradas em IRPS, no período de 2008 a 2015, observada no Quadro III, admitiu um crescimento médio na ordem de 2,2\%, traduzido em 102.712 milhares de Escudos Cabo-Verdianos (ECV). Esta oscilação resultou dos seguintes fatores:

1. O aumento das receitas cobradas em 2008, em relação ao ano anterior, na percentagem de $7 \%$ e no valor de 319.510 milhares de ECV, resultou de maiores rendimentos dos contribuintes em 2007 (PCGE, 2008);

2. A redução das receitas cobradas em 2009 , na percentagem de $-7,7 \%$ e no valor negativo em 371.318 milhares de ECV, resultou da redução substancial da carga fiscal, a nível dos rendimentos auferidos pelas famílias (PCGE, 2008);

3. O aumento das receitas cobradas em 2010, na percentagem de 4,3\% e no valor de 191.810 milhares de ECV, resultou de "medidas tomadas no âmbito de reforço da fiscalização e no aumento de notificação aos contribuintes faltosos" (CGE, 2010, p. 85). Apesar do aumento das receitas em 2010, constatou-se que há um deficiente controlo da dívida fiscal, face ao cumprimento da entrega do IRPS (PCGE, 2010); 
4. O aumento das receitas cobradas em 2011, na percentagem de 5\% e no valor de 231.833 milhares de ECV, resultou do reforço da atividade de controlo e fiscalização e do aumento de notificações aos contribuintes faltosos, (PCGE, 2008). Contudo, em 2011 foram constatados insuficiências na consolidação de dívida, devido à falta de controlo nas Repartições de Finanças, erros e insuficiências na passagem das dívidas para o cadastro dos contribuintes, permanência no cadastro, de contribuintes que cessaram as suas atividades, e stock de cheques sem cobertura que foram utilizados pelos contribuintes para pagar imposto (PCGE, 2011). De acordo com informações fornecidas pela Unidade de Tecnologias de Informação e Comunicação (UTIC), o problema de cheques sem cobertura já foi resolvido, sendo que, atualmente, qualquer meio de pagamento utilizado para quitar as dívidas fiscais gera um pagamento provisório, que posteriormente é certificado pelo sistema do Tesouro Público e a dívida só se considera quitada após esta certificação;

5. Não obstante as receitas cobradas em 2012 terem aumentado, o crescimento destas receitas foi apenas de 2,4\%, equivalente a 116.684 milhares de Escudos Cabo-Verdianos (ECV), quando no ano anterior o referido crescimento foi de 5\%. Esta redução de crescimento resultou da "crise financeira internacional, cujos efeitos se fizeram sentir na atividade económica em 2012" (PCGE, 2012, pp. 100-101);

6. A redução das receitas cobradas em 2013, que baixaram de 2,4\% para 4,2\% negativo, traduzida em valor negativo de 200.326 milhares de ECV, resultou da redução de imposto das famílias com menor poder de compra (PCGE, 2013);

7. Em 2014 houve um aumento das receitas cobradas na percentagem de 4,3\% e no valor de 205.036 milhares de ECV, não obstante, se ter verificado, uma ineficiência da administração fiscal, na cobrança de dívidas e no registo real das importâncias por cobrar (PCGE, 2014);

8. O aumento das receitas cobradas em 2015, na percentagem de $6,6 \%$ e no valor de 328.463 milhares de ECV, resultou da entrada em 
vigor do novo Código de IRPS, que permitiu "alargar a base tributária e aumentar a eficácia fiscal” (PCGE, 2015, p. 153).

No delineamento da origem das receitas de IRPS expurgadas na análise documental, foi constatado que a Direção Nacional de Receitas do Estado não tem protocolos com outras instituições, que permitam fornecer informações sobre as receitas de IRPS que circulam no país, nomeadamente o Instituto Nacional da Previdência Social, o Instituto Nacional de Estatística, o serviço de Registos, Notariado e Identificação, entre outras.

No sentido de preconizar propostas de medidas que permitam aumentar a cobrança do IRPS, é apresentado de seguida o stock de dívidas de IRPS, de forma a observar o alcance destas dívidas e delinear medidas necessárias para garantir a cobrança das mesmas. Neste âmbito, é apresentado de seguida o Gráfico I.

\section{Gráfico I}

Stock de dívidas sobre receitas cobradas

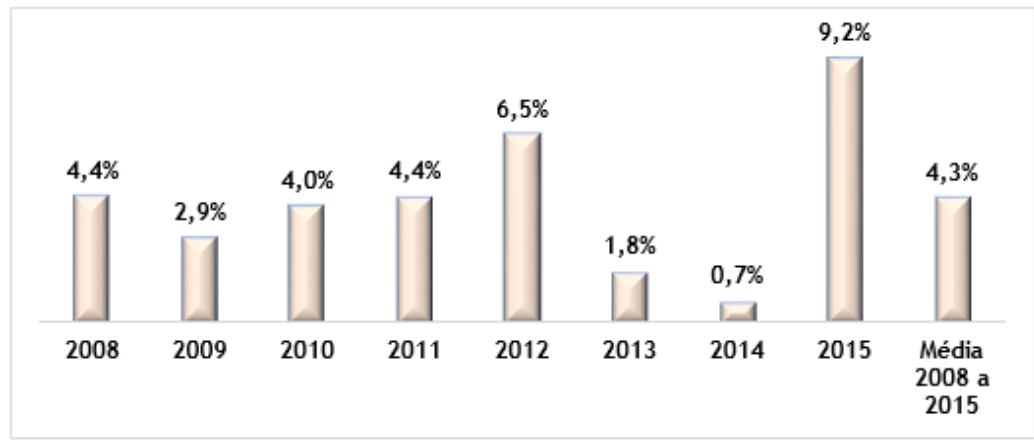

Fonte: Dados de PCGE (2008 a 2015)

O Gráfico I anteriormente apresentado demonstra que o stock de dívidas, do IRPS sobre o total das receitas do IRPS cobrado, no período de 2008 a 2015, atingiu o seu auge em 2015 (9,2\%). De acordo com informações fornecidas pela Unidade de Tecnologias de Informação e Comunicação (UTIC), esta ocorrência resultou do facto do ano 2015 ser o primeiro em que os próprios contribuintes passaram a apurar os seus impostos e a submeter a declaração eletrónica de rendimentos. 
Estes resultados permitiram-nos apresentar as seguintes propostas de medidas para melhorar a cobrança do Imposto Sobre o Rendimento das Pessoas Singulares (IRPS), tendo em consideração que estas propostas vão permitir à administração fiscal identificar rendimentos não declarados, depurar o correspondente imposto e proceder à respetiva cobrança.

1. Aprimorar o sistema de controlo da dívida fiscal, face ao cumprimento da entrega do IRPS retido pelas pessoas coletivas, de forma a suprir a correspondente deficiência elencada pelo Tribunal de Contas. Este controle pode ser feito através da introdução de um sistema de acompanhamento permanente, dos processos dos contribuintes, que permita identificar aqueles que não cumpram com as suas obrigações fiscais, nomeadamente a obrigação da entrega do imposto retido na fonte;

2. Investir fortemente no cruzamento de informações que permita reaver o imposto não declarado, por exemplo, através da assinatura de protocolos com outras instituições públicas, tais como o Instituto Nacional da Estatística (INE), o Serviço de Registo Notariado e Identificação (RNI) e o Instituto Nacional de Previdência Social (INPS). São protocolos que permitam aceder a informações destas instituições e depurar elementos que possibilitem identificar rendimentos não declarados pelos contribuintes;

3. Proceder ao cruzamento de informações, entre os rendimentos declarados pelos contribuintes e os valores declarados pela fonte pagadora destes rendimentos;

4. Proceder à purificação das dívidas fiscais, por cada Repartição de Finanças, assim como a cobrança destas dívidas, de forma a suprir as deficiências detetadas no PCGE (2011), que até à atual data estão presentes na instituição, conforme informações fornecidas pela UTIC, ou seja, deficiências resultantes de insuficiência na consolidação de dívidas fiscais de IRPS, devido à falta de controlo nas Repartições de Finanças, deficiência de erros e insuficiências na passagem das dívidas para o cadastro fiscal, assim como a permanência de contribuintes no cadastro que já cessaram as suas atividades, conforme relata o PCGE (2011) / (2014); 
5. Proceder à consolidação mensal das informações referentes as receitas fiscais arrecadadas, de acordo a recomendação do PCGE (2008) / (2009), que até a presente data não foi cumprida, conforme informações fornecidas pela UTIC. O cumprimento desta recomendação vai instigar o controlo de stock de dívidas e induzir a determinação de medidas para aumentar a cobrança;

6. Investir na educação fiscal aos contribuintes, com vista a revelar as vantagens de pagamento de impostos para o desenvolvimento do país e incitar os contribuintes incumpridores a pagar os seus impostos.

\section{CONCLUSÕES}

Este estudo teve como principais objetivos, enquadrar a evolução do Imposto sobre o Rendimento das Pessoas Singulares (IRPS) em Cabo Verde, desde a época colonial até a atualidade, e verificar a oscilação deste imposto no período de 2008 a 2015, tendo em vista delinear propostas de medidas para melhorar a sua cobrança, com base na exploração de informações produzidas pelo Tribunal de Contas de Cabo Verde e na análise de informações recolhidas na Direção Nacional de Receitas do Estado.

Em relação ao IRPS, foi observado que no período de 2008 a 2015 a oscilação deste imposto traduziu-se num acréscimo médio de receitas em 102.712 (cento e dois mil, setecentos e doze) milhares de Escudos CaboVerdianos (ECV), equivalente a uma média, em percentagem, de 2,2\%, não obstante o stock médio de dívidas neste mesmo período equivaler a $4,3 \%$ das receitas cobradas em IRPS. Neste contexto, as propostas de medidas para aumentar a cobrança deste imposto envolvem, o aperfeiçoamento do sistema de controlo da dívida fiscal, sendo que, este controlo pode ser feito através da introdução de um sistema de acompanhamento permanente dos processos dos contribuintes, com vista a identificar aqueles que não cumprem com as suas obrigações fiscais, nomeadamente a obrigação da entrega do imposto retido na fonte. Igualmente, envolvem uma forte aposta no cruzamento de informações de forma a reaver o imposto não declarado, situação que pode ser resolvida através da assinatura de protocolos com outras instituições públicas, que 
permitam aceder às informações destas instituições e depurar elementos que visem identificar rendimentos não declarados pelos contribuintes. Adicionalmente, o cruzamento de informações envolve a observação dos rendimentos declarados pelos contribuintes, em comparação com os valores declarados pela fonte pagadora destes rendimentos. No âmbito das referidas propostas, é de realçar a introdução de mecanismos que permitam proceder à purificação das dívidas fiscais por cada Repartição de Finanças e a cobrança destas dívidas. Outrossim, as referidas propostas incluem a deliberação de regras que permitam proceder à consolidação mensal de informações, referentes a receitas fiscais arrecadadas, no fito de instigar o controlo de stock de dívidas e induzir a determinação de medidas para aumentar a cobrança. Finalmente, outra medida aconselhável prende-se com um forte investimento na educação fiscal, direcionada para motivar o pagamento de imposto e para a inserção de boas práticas educativas nas escolas, que proporcionem aos estudantes o conhecimento dos seus direitos e obrigações fiscais, de forma a alavancar o pagamento de impostos futuros.

\section{REFERÊNCIAS BIBLIOGRÁFICAS}

Abrantes, J. A. (2011). A ergonomia cognitiva e as inteligências múltiplas. Simpósio de excelência em gestão e tecnologia - SEGET (pp.1-14). Rio do janeiro: UERJ.

Banco de Portugal - Evolução das economias dos PALOP e de TimorLeste. (2015). 25 anos de cooperação. Lisboa: Eurosistema. Consultado em 21 de junho de 2018, de https://www.bportugal.pt/publications/banco-de-portugal/all/385.

Bicho, A. C., \& Magno, M. H. (2007). Manual do Imposto sobre o Rendimento das Pessoas Singulares. Lisboa: Ministério das Finanças e da Administração Pública - Direção Geral dos Impostos.

Campos, F. V. (2017). Sistemas de gestão de receitas do Estado Cadastro. Relatório de assistência técnica - estudo apresentado pelo FMI a DNRE para efeito de saneamento do cadastro fiscal. Departamento de Finanças Públicas, Cabo Verde. pp. 1-45.

Cardina, J. G. (1999). Reflexões sobre a Lei Geral Tributária. Revista Gestão e Desenvolvimento, 8, 179-201. Consultado em 28 de junho de 
2019 ,

http://z3950.crb.ucp.pt/Biblioteca/GestaoDesenv/GD8/gestaodesenv olvimento8ind.pdf.

Catarino, J. R., \& Soares, R. M. (2017). Desigualdades de esforço fiscal no imposto de renda das pessoas físicas. Revista Seqüência (Florianópolis), 76, 37-68. Consultado em 29 de junho de 2018, de http://www.scielo.br/pdf/seq/n76/2177-7055-seq-76-00037.pdf.

CGE 2010 - Conta Geral do Estado de 2010. (2011). Ministério das Finanças e do Planeamento. Cabo Verde.

Cellard, A. (2008). A análise documental. In J. Poupart et al. A pesquisa qualitativa: enfoques epistemológicos e metodológicos (pp. 295-316). Petrópolis, RJ. Vozes.

Coutinho, C., \& Chaves, J. (2002). O estudo de caso na investigação em tecnologia educativa em Portugal. Revista Portuguesa de Educação, 15 (1), 221-243. Consultado em 2 de março de 2017, de https://repositorium.sdum.uminho.pt/bitstream/1822/492/1/ClaraCou tinho.pdf.

De Paula, L. F. \& Ferrari, F. (2011). Desdobramentos da crise financeira internacional. Revista de Economia Política, 31 (2), 315-335. Consultado em 25 de junho de 2018, de 2018, de www.scielo.br/scielo.php?script=sci_arttext\&pid=S010131572011000200009.

DNRE - Direção Nacional de Receitas do Estado. 2017. Inquérito a satisfação dos colaboradores da DNRE. INE. Cabo Verde.

Fortin, M. F. (2009). O Processo de investigação, da concepção à realização $\left(5^{\mathrm{a}}\right.$ ed.). Loures: Lusociência - Edições Técnicas e Científicas, Lda.

INE - Instituto Nacional de Estatística - Departamento de Contas Nacionais. (2013). Como se Calcula o PIB. Statistics Portugal.

Portal DNRE. (2017). Direção Nacional de Receitas do Estado. Consultado em 1 de julho de 2017, de https://www.dnre.gov.cv/dnre/pt-pt/sobre.

Vasques, S. (2016). A introdução do IVA em Cabo Verde. In Miranda, J. Estudos Jurídicos e Económicos em Homenagem ao Prof. Doutor António de Sousa Franco III (pp. 953-967). Coimbra: Coimbra Editora. 


\section{CóDIGOS}

Código Geral Tributário, aprovado pela Lei n. ${ }^{\circ}$ 37/IV/92, de 28 de janeiro (I ed.). (1993). Ministério das Finanças - DGCI. Cabo Verde.

Código de Processo Tributário, aprovado pela Lei n. ${ }^{\circ}$ 19/93, de 29 de março (I ed.). (1993). Ministério das Finanças - DGCI. Cabo Verde.

\section{LEGISLAÇÕES}

CLNU - Coleção da Legislação Novíssima do Ultramar de 1901. (1902). Regulamento geral da administração da fazenda, da sua fiscalização superior e da contabilidade pública nas províncias ultramarinas: Aprovado pelo Decreto de 3 de outubro de 1901. Companhia Typographica, XXIX, 865-938. Consultado em 28 de novembro de 2017 , de http://www.governodosoutros.ics.ul.pt/imagens_livros/bcu_novissim a_vol29/Legisla\%C3\%A7\%C3\%A3o\%20Nov\%C3\%ADssima\%20\%20XXIX\%20Volume\%20-\%201901.pdf.

CRCV - Constituição da República de Cabo Verde, aprovada pela Lei n. ${ }^{\circ}$ 3/80. (2010). 2. ${ }^{a}$ Revisão Ordinária. Cabo Verde: Assembleia Nacional.

Decreto-Lei n. ${ }^{\circ} 44$ 561, de 10 de setembro de 1962 - aprova o imposto de capitais. Diário do Governo - I Série n. ${ }^{\circ}$ 208. Imprensa Nacional. Portugal.

Decreto-Lei n. ${ }^{\circ} 11-\mathrm{A} / 77$, de 28 de janeiro - cria o imposto de capitais. 2. $^{\circ}$ Suplemento do Boletim Oficial n. ${ }^{\circ}$ 28/1977. INCV. Cabo Verde.

Decreto-Lei n. ${ }^{\circ} 11-\mathrm{B} / 77$, de 28 de janeiro - cria o imposto sobre os rendimentos de petróleos. $2 .^{\circ}$ Suplemento, Boletim Oficial n. ${ }^{\circ}$ 28/1977. INCV. Cabo Verde.

Decreto-Lei n. ${ }^{\circ}$ 1/96, de 15 de janeiro - Regulamento do Imposto Único sobre o Rendimento. Boletim Oficial $n .^{\circ} 1 / 96$ - I Série. INCV. Cabo Verde.

Decreto-Lei n. ${ }^{\circ} 35 / 2013$, de 24 de setembro - cria um regime excecional de regularização das dívidas contraídas entre o Estado e o 
Contribuinte. Suplemento do Boletim Oficial n. ${ }^{o}$ 50/2015 - I Série. INCV. Cabo Verde.

Decreto-Lei n. ${ }^{\circ}$ 72/2015, de 31 de dezembro - aprova um regime excecional de regularização de dívidas de natureza fiscal cujo prazo legal de cobrança termina até 31 de dezembro de 2015. Suplemento do Boletim Oficial n. ${ }^{\circ}$ 86/2015 - I Série. INCV. Cabo Verde.

Decreto n. ${ }^{\circ}$ 129/77, de 31 de dezembro - aprova o Regulamento do imposto sobre a aplicação de capitais. 2. ${ }^{\circ}$ Suplemento, Boletim Oficial n. ${ }^{\circ}$ 53/77. Imprensa Nacional. Cabo Verde.

Decreto n. ${ }^{\circ}$ 130/77, de 31 de dezembro - aprova o Regulamento do imposto sobre os rendimentos de petróleo e seus derivados. 2. ${ }^{\circ}$ Suplemento, Boletim Oficial n. ${ }^{\circ}$ 53/77. INCV. Cabo Verde.

Diploma Legislativo n. ${ }^{\circ} 1542$, de 12 de junho de 1963 - aprova o novo Regulamento da Contribuição Industrial. Suplemento Boletim Oficial $n .^{\circ}$ 23/1963 - I Série. INCV. Cabo Verde.

Diploma Legislativo n. ${ }^{\circ} 1543$, de 12 de junho de 1963 - aprova o Regulamento do Imposto Profissional. Suplemento Boletim Oficial $n .^{o}$ 23/1963 - I Série. INCV. Cabo Verde.

Diploma Legislativo n. ${ }^{\circ} 1544$, de 12 de junho de 1963 - aprova o Regulamento da Contribuição Predial. Suplemento Boletim Oficial $n .^{o}$ 23/1963 - I Série. INCV. Cabo Verde.

Diploma Legislativo n. ${ }^{\circ} 1545$, de 12 de junho de 1963 - aprova o Regulamento do Imposto Complementar sobre os rendimentos. Suplemento Boletim Oficial n. ${ }^{\circ}$ 23/1963 - I Série. INCV. Cabo Verde.

Lei n. ${ }^{\circ} 77 / \mathrm{V} / 98$, de 7 de dezembro - Lei de enquadramento orçamental. Boletim Oficial n. ${ }^{\circ}$ 45/1998 - I Série. INCV. Cabo Verde.

Lei n. ${ }^{\circ}$ 78/VIII/2014, de 31 de dezembro - aprova o Código do Imposto sobre o Rendimento das Pessoas Singulares. Boletim Oficial $n .^{o}$ 81/2014 - I Série. INCV. Cabo Verde.

Lei n. ${ }^{\circ} 82 / V I I I / 2014$, de 8 de janeiro - aprova o Código do Imposto sobre o Rendimento das Pessoas Coletivas. Boletim Oficial n. ${ }^{o}$ 3/2014 - I Série. INCV. Cabo Verde.

Portaria n. ${ }^{\circ} 78 / 2015$, de 31 de dezembro - aprova os modelos da declaração anual de rendimentos das pessoas coletivas e das pessoas singulares. Boletim Oficial n. ${ }^{\circ}$ 86/2014 - I Série. INCV. Cabo Verde. 
RII - Regulamento do Imposto Industrial, aprovado pelo Decreto-Lei n. ${ }^{\circ}$ 147/92, de 30 de dezembro (I ed.). (1993). Direção Geral das Contribuições e Impostos. Cabo Verde.

Regulamento do Imposto Complementar, aprovado pelo diploma Legislativo n. ${ }^{\circ} 1545$, de 12 de junho de 1963 (I ed.). (1993). DGCI. Cabo Verde.

\section{PARECERES}

PCGE 2008 - Parecer sobre a Conta Geral do Estado de 2008. (2011). Tribunal de Contas. Cabo Verde: Tribunal de Contas.

PCGE 2009 - Parecer sobre a Conta Geral do Estado de 2009. (2012). Tribunal de Contas. Cabo Verde: Tribunal de Contas.

PCGE 2010 - Parecer sobre a Conta Geral do Estado de 2010. (2013). Tribunal de Contas. Cabo Verde: Tribunal de Contas.

PCGE 2011 - Parecer sobre a Conta Geral do Estado de 2011. (2014). Tribunal de Contas. Cabo Verde: Tribunal de Contas.

PCGE 2012 - Parecer sobre a Conta Geral do Estado de 2012. (2015). Tribunal de Contas. Cabo Verde: Tribunal de Contas.

PCGE 2013 - Parecer sobre a Conta Geral do Estado de 2013. (2016). Tribunal de Contas. Cabo Verde: Tribunal de Contas.

PCGE 2014 - Parecer sobre a Conta Geral do Estado de 2014. (2017). Tribunal de Contas. Cabo Verde: Tribunal de Contas.

PCGE 2015 - Parecer sobre a Conta Geral do Estado de 2015. (2018). Tribunal de Contas. Cabo Verde: Tribunal de Contas. 